\title{
A simple surgical technique for closure of apical muscular ventricular septal defect
}

\author{
Amit Mishra, MCh, FPCS, Ritesh Shah, MD, Manan Desai, MCh, Ajay Chourasiya, MCh, \\ Hardik Patel, MBBS, Nilesh Oswal, MD, and Dayesh Rodricks, DPT
}

\begin{abstract}
Objective: Ventricular septal defect (VSD) is among the most common congenital heart diseases encountered in pediatric cardiac patients. Apical muscular VSD constitutes nearly $2 \%$ of defects, which may or may not be associated with other congenital heart defects. The purpose of our study is to present our innovative and simple surgical technique using custom-made low-profile polytetrafluoroethylene (PTFE) single disc device for closing multiple apical muscular and isolated apical muscular VSD.
\end{abstract}

\begin{abstract}
Method: Between January 2010 and July 2013, 17 patients with isolated or multiple apical muscular VSDs with or without associated heart diseases underwent operation at our institute. The apical VSD was closed using our custom-made low-profile single disc polytetrafluoroethylene device. The operative technique and the technique used to prepare the single disc device are detailed.
\end{abstract}

Results: Seventeen patients of ages ranging from 3 months to 7 years underwent operation over 3 years. One 8-month-old patient with transposition of the great arteries with multiple VSDs died after 35 days due to severe pulmonary artery hypertension and sepsis. Another newborn infant with infracardiac total anomalous pulmonary venous connection with a 4-mm apical VSD also died after 3 days because this VSD could not be identified. All other patients are doing well on follow-up.

Conclusions: The technique described by us has the advantage of apical VSD closure through the left ventricle without left ventriculotomy. Our technique is simple and cost-effective. (J Thorac Cardiovasc Surg 2014;148:2576-9)

Ventricular septal defect (VSD) is a common congenital heart disease encountered in pediatric cardiac practice; nearly $2 \%$ of all VSDs are apical. They may be isolated or multiple, although apical VSDs are rarely in isolation, and they are usually associated with 1 or more other congenital heart diseases. Although indications and techniques for closing different types of VSDs surgically and by interventions are by and large standardized, there has been a rapid increase in incidence of catheter-based and perventricular closure of muscular VSD. Because the technique for closing apical muscular VSD is still a matter of debate, we present our innovative and simple surgical technique for closing apical VSD using our cost-effective, custom-made low-profile single disc polytetrafluoroethylene (PTFE) device.

From the Department of Cardiovascular and Thoracic Surgery, U. N. Mehta Institute of Cardiology and Research Center (affiliated with BJ Medical College, Ahmedabad), Gujarat, India.

Disclosures: Authors have nothing to disclose with regard to commercial support.

Received for publication Sept 27, 2013; revisions received Feb 4, 2014; accepted for publication Feb 10, 2014; available ahead of print March 22, 2014.

Address for reprints: Amit Mishra, MCh, FPCS, Department of Cardiovascular and Thoracic Surgery, U. N. Mehta Institute of Cardiology and Research Center, New Civil Hospital Campus, Asarwa, Ahmedabad-380016, Gujarat, India (E-mail: drmishraamit@yahoo.com).

$0022-5223 / \$ 36.00$

Copyright (c) 2014 by The American Association for Thoracic Surgery

http://dx.doi.org/10.1016/j.jtcvs.2014.02.036

\section{CASE DETAILS}

Seventeen patients with multiple and isolated apical VSD with or without associated heart defects underwent operation at our institution between January 2010 and July 2013. All patients were diagnosed on the basis of clinical history, examination, electrocardiography, and 2-dimensional echocardiography. Cardiac catheterization was done to assess the operability and, if needed, angiography to confirm the anatomy of the defects. The hospital ethics committee approved the study protocol. Written consent was obtained from both parents, who were informed about the nature, the advantages, and the disadvantages of the procedure.

\section{MATERIAL AND METHOD}

The disc device (Figure 1, $A$ and $B$ ) was prepared before surgery in the operating room.

The device has 2 parts: a disc and a shaft. The circular disc is made from 2 patches: 1 patch of expanded PTFE (ePTFE) (Gor-Tex patch, W. L. Gore, Flagstaff, Ariz) of thickness $0.6 \mathrm{~mm}$ and another patch of PTFE felt (CR Bard, Inc, Delran, NJ) of thickness $0.8 \mathrm{~mm}$ that are sutured to each other. The total thickness of the disc is nearly $1.4 \mathrm{~mm}$ and its diameter is nearly twice the maximum diameter of the VSD. The shaft is also made from a 2- to 2.5-cm long ePTFE tube (CR Bard, Inc, Delran, NJ) of the same diameter as the maximum size of the VSD. The graft is sutured to the center of the disc in an end-to-side fashion on the Teflon felt side (septal surface of device) using continuous monofilament polypropylene suture and is reinforced at 2 to 3 points. Two extra disc devices with graft sizes $1 \mathrm{~mm}$ above and below the required size of the device are also kept ready. 

Abbreviations and Acronyms
$\mathrm{CPB}=$ cardiopulmonary bypass
ePTFE $=$ expanded polytetrafluoroethylene
$\mathrm{LV}=$ left ventricular
PTFE $=$ polytetrafluoroethylene
TEE $=$ transesophageal echocardiography
VSD $=$ ventricular septal defect

The device is kept in normal saline $(0.9 \%)$ before use to avoid any air trapping between the 2 discs.

\section{Surgical Technique}

Intraoperative transesophageal echocardiography (TEE) and/or transthoracic echocardiography was performed in all patients to confirm the size, number, and position of VSD in relation to the moderator band (Figure 2). The VSD size was measured in 4-chamber and long axis view, the larger of the 2 values was considered for device selection.

After cardioplegic arrest and right atriotomy, the interatrial septum was widely opened. In all cases, a right angle forcep was used to gently probe the apical part of the ventricular septum at the expected site of the apical VSD (Figure 2, $A$ ). This angle forcep was passed through the defect and an assistant retracted the mitral valve through the interatrial septum (Figure 2,B). After confirming its position through the defect, the device was caught and held with the help of a right angle forcep (Figure 2, C) and its shaft was gently pulled through the ventricular septum (Figure 2, $D$ ), taking care to avoid injuring the neighboring anterior papillary muscle or the moderator band. An illuminating dental mirror was used to confirm the latter and accurate positioning of the device (Figure 2, F). The shaft of the device was sutured at its base to the septal muscles adjacent to the VSD/ moderator band using 2 interrupted pledgeted polypropylene sutures closing the lumen of the graft (Figure 2,E). The remaining portion of the shaft was excised. In 1 patient 2 disc devices were used because the VSD was 16 $\mathrm{mm}$ in size with 2 openings in front and behind the moderator band. The procedure takes approximately 15 to 20 minutes.

Associated cardiac defects were corrected in the usual fashion and after weaning from cardiopulmonary bypass (CPB), TEE/epicardial echocardiography was routinely performed to confirm adequate repair. Routine blood samples were drawn from right atrium and pulmonary artery and oxygen saturation was checked in all patients, keeping the fractional inspired oxygen at $50 \%$. Step-up $>5 \%$ was considered significant.

\section{RESULTS}

An 8-month-old patient with transposition of the great arteries with multiple VSDs died after 35 days due to severe pulmonary artery hypertension and sepsis. However, in a $2.7-\mathrm{kg}$ patient with infracardiac total anomalous pulmonary venous connection the apical VSD could not be identified. This patient later died on the third postoperative day due to severe pulmonary artery hypertension. Occasionally we found tiny turbulence between the disc and the septum and occasionally we noticed a tiny leak around the shunt graft during the immediate postoperative period without significant left to right shunt, which usually disappeared in a day or 2. All had step-up of $<5 \%$, except in a patient who had multiple tiny residual VSD who underwent pulmonary artery debanding and multiple VSD closure with step-up of $8.2 \%$ for which nothing was done because the patient was hemodynamically stable. CPB was reinstituted in 2 patients. In 1 patient who had moderate mitral regurgitation on TEE, the oversize disc was flattering and was interfering with the closure of mitral valve, so the disc was reduced in size. In that patient the diameter of the disc was nearly 2.5 times the diameter of the VSD. In another patient CPB was reinstituted because there was an additional undiagnosed posterior muscular VSD. Both patients recovered uneventfully. No patient had heart block arrhythmia, hemolysis, or any neurologic complications. Median intensive care unit stay was 4 days (range, 2-35 days). Median hospital stay was 11 days (range, 10-35 days). Median follow-up was 12 months (range, 6-30 months) and was complete. At last follow-up, no patient has required reintervention or developed a device-related complication. Follow-up echocardiograms reveal no residual left-to-right shunt.

\section{DISCUSSION}

VSD is the most common congenital heart disease encountered in pediatric cardiology clinics. Nearly $2 \%$ of VSDs are apical; they may be single or multiple. Apical VSD may be isolated but is usually associated with some other congenital heart diseases. Various standard surgical techniques and interventions are available to close different types of VSD. Technique for closure of apical VSD is still a subject of debate. There is a rapid increase in percutaneous and perventricular closure of muscular VSD. The anatomy of apical septum and echocardiographic assessment was explained in detail by Kumar and colleagues. ${ }^{1}$ Because the apical septum is the most distal part of the septum and it has trabeculations on the right ventricular side, it is difficult to visualize the margins of the defect clearly from the right ventricular aspect of the septum through the tricuspid valve. The space at the apex is also limited, hence it is difficult to close the defect from the right atrium., ${ }^{2,3}$

The technique of closing an apical VSD through left ventriculotomy was described by Aaron and colleagues. ${ }^{4}$ The identification of apical VSD through left ventriculotomy is easy because the left ventricular side of the septum is smooth with no papillary muscle attachment. An apical VSD usually has a solitary opening on the left ventricular (LV) side of the septum. Left ventriculotomy carries the risk of late ventricular aneurysm formation, myocardial dysfunction, and arrhythmias. ${ }^{5}$ Right ventriculotomy is less dangerous but it may be difficult to find the true margins of the defect between the coarse trabeculations, especially in patients who have pulmonary stenosis.

Earlier we were also closing apical septal defects through right ventriculotomy. Right ventriculotomy may increase the risk of postoperative right ventricular dysfunction, ${ }^{6}$ especially when apical VSD is associated with conditions like tetralogy of Fallot, transposition of the great arteries, VSD with pulmonary stenosis, and multiple VSD with single 

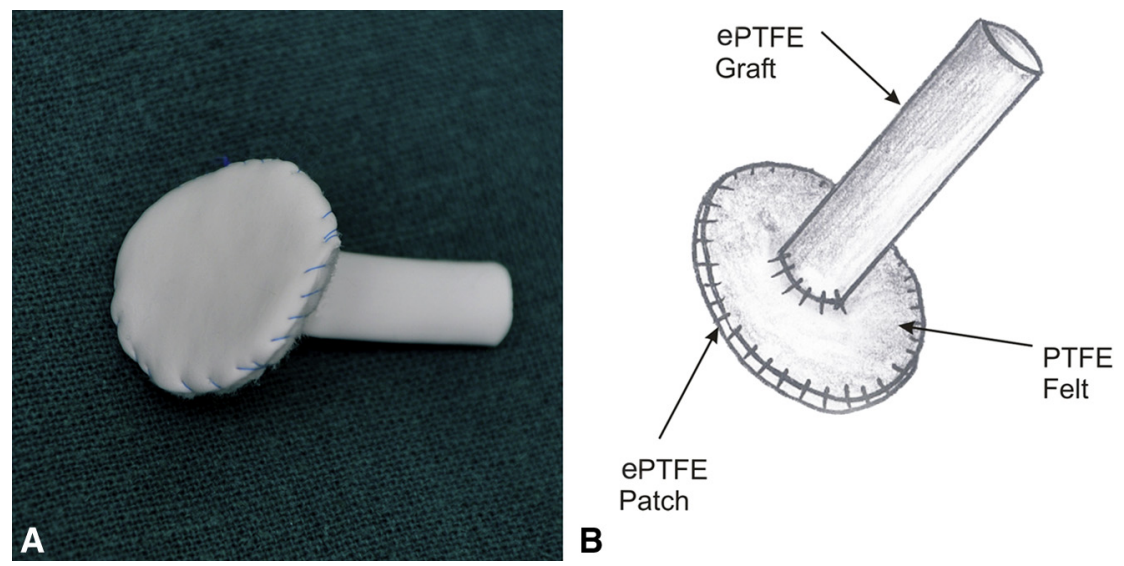

FIGURE 1. A, Photograph of disc device. B, Diagram of disc device. ePTFE, Expanded polytetrafluoroethylene; PTFE, polytetrafluoroethylene.

pulmonary artery. Ootaki and colleagues ${ }^{7}$ described the sandwich technique for closing trabecular VSD in 11 patients. However 3 of their patients had significant residual shunt. We believe that it is difficult to stitch at the apical portion of the septum. The only advantage we see of our technique is that the shaft of the device obliterates the VSD and thus the incidence of residual shunt is least with our technique.

Initial attempts at intraoperative device closure of muscular VSD in patients in whom percutaneous closure was contraindicated (eg, small infants) had unsatisfactory results with mortality and failure rates as high as $14 \%$ to $25 \%$ and $20 \%$ to $40 \%$, respectively. ${ }^{8-11}$

Hybrid procedures and perventricular device closures are increasingly gaining popularity in closing muscular
VSDs, with good results in isolated VSD as well as in patients with associated congenital heart defects. ${ }^{12}$ Perventricular device closure of VSD has its own limitations, including some anatomical variations of muscular defects like high posterior muscular defects, distal apical defects, and misaligned defects where it is difficult to get access and there is no space for deployment of the right ventricle side of the disc, ${ }^{12,13}$ which is not a limitation of our device. Perventricular VSD closure is also associated with ventricular arrhythmias, LV pseudoaneurysm formation, ${ }^{14} \mathrm{LV}$ dysfunction, ${ }^{16}$ incomplete right ventricle disc expansion with the screw of the disc protruding into the pericardium, ${ }^{12,15}$ and hemolysis in the presence of residual shunt. ${ }^{13}$
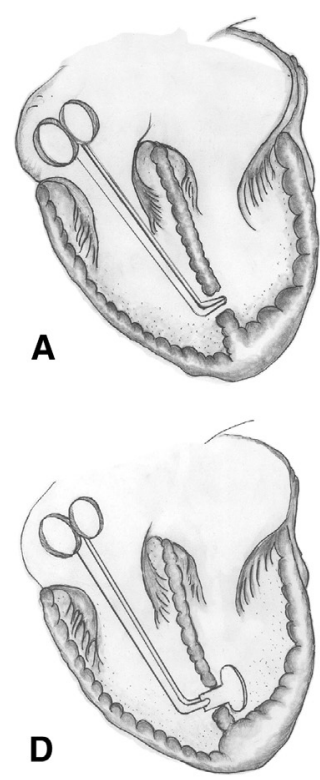

B

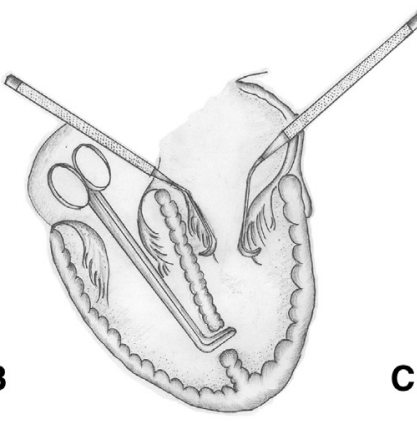

C

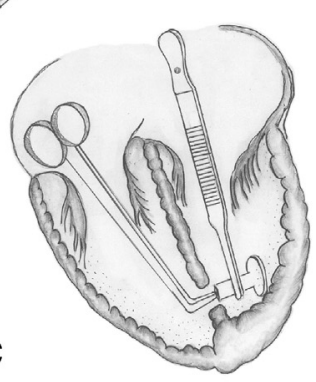

E

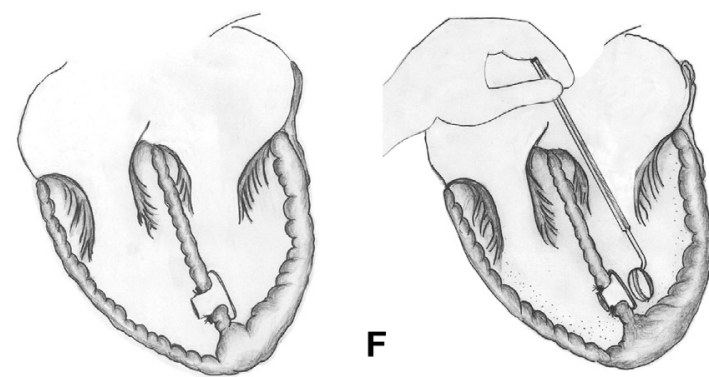

FIGURE 2. A, A right angle forceps probed into the VSD. B, Position confirmed while an assistant retracts the mitral valve. C, Right angle forceps now holds the shaft of the device. D, The shaft of the device is pulled through the VSD avoiding injury to mitral subvalvular apparatus and moderator band. E, The device fixed to the RV side of the septum obliterating the graft. F, Position of VSD confirmed with the help of dental mirrors. 
The PTFE device (GORE HELEX Septal Occluder) ${ }^{17}$ is available for easily closing atrial septal defects using the transcatheter technique. The PTFE is also used to close the VSD in operating theaters. We combined the PTFE and ePTFE-both of which are readily available in operating theaters-to prepare our indigenous device. The PTFE (Teflon felt) material is soft and spongy, which provides a cushion effect on the septal surface of the device.

The device works in 3 ways for prevention of left to right shunt across the VSD. First, the graft itself obliterates the VSD, because the size of the graft is the same as that of VSD. Second, the disc will also cover the LV side of septum as well as the surrounding area of the VSD. Third, the right ventricular side of the graft is closed with pledgeted stitches with surrounding septal muscles; hence any residual left to right shunt cannot occur around the graft. Multiple apical VSDs usually have a single opening on the left side septum, so closure of apical VSD will also close all other apical VSDs. If any additional VSD is present in the vicinity of the apical VSD, it will also be covered by the disc. The LV surface is smooth and does not have any attachment of papillary muscles so the disc gets firmly adhered to the LV side of the septum. The high pressure in the LV also keeps the disc in its position. Only if the diameter of the disc is more than twice the diameter of the VSD may we see the flattering movement of the disc, as noticed in 1 of our patients. Our disc device being low profile does not interfere with the geometry/contraction of the LV.

Our custom-made device can be tailored and prepared in-house in 10 minutes. Finally, the cost of our single disc device is $\$ 100$, whereas the cost of a commercially available device is nearly $\$ 1300$. The use of our device would therefore drastically bring down the expense of the total procedure and make it significantly more affordable for patients of lower economic strata.

\section{CONCLUSIONS}

The technique we described has the advantage of apical VSD closure through the LV without left ventriculotomy. Our technique is simple and cost-effective.

The authors thank Naisargi Patel, Sanjay Patel, Himani Pandya, Nrupa Kumthekar, Hiral Surti, and Piyushbhai Solanki for help in preparing the manuscript and also thank Jyotsna Bhatnanagar for patiently plodding through a maze of scientific jargon and making it comprehensible.

\section{References}

1. Kumar K, Lock JE, Geva T. Apical muscular ventricular septal defects between the left ventricle and the right ventricular infundibulum. Diagnostic and interventional considerations. Circulation. 1997;95:1207-13.

2. Kirklin JK, Castaneda AR, Keane MD, Fellows KE, Norwood WI. Surgical management of ventricular septal defects. J Thorac Cardiovasc Surg. 1980;80: 485-93.

3. Kitagawa T, Durham LA, Mosca RS, Bove EL. Techniques and results in the management of multiple ventricular septal defects. J Thorac Cardiovasc Surg. 1998; 115:848-56.

4. Aaron BL, Lower ER. Muscular ventricular septal defect repair made easy. Ann Thorac Surg. 1975;19:568-70.

5. Hanna B, Colan SD, Bridges ND, Mayer JE, Castaneda A. Clinical and myocardial status after left ventriculotomy for ventricular septal defects. J Am Coll Cardiol. 1991;17(Suppl):110A.

6. Seddio F, Reddy VM, McElhinney DB, Tworetzky W, Silverman NH, Hanley FL. Multiple ventricular septal defects: how and when should they be repaired? J Thorac Cardiovasc Surg. 1999;117:134-9.

7. Ootaki Y, Yamaguchi M, Yoshimura N, Oka S, Yoshida M, Hasegawa T. Surgical management of trabecular ventricular septal defects: the sandwich technique. J Thorac Cardiovasc Surg. 2003;125:508-12.

8. Chaturvedi RR, Shore DF, Yacoub M, Redington AN. Intraoperative apical ventricular septal defect closure using a modified Rashkind double umbrella. Heart 1996;76:367-9.

9. Okubo M, Benson LN, Nykanen D, Azakie A, Van Arsdell G, Coles J, et al Outcomes of intraoperative device closure of muscular ventricular septal defects. Ann Thorac Surg. 2001;72:416-23.

10. Fishberger SB, Bridges ND, Keane JF, Hanley FL, Jonas RA, Mayer JE, et al. Intraoperative device closure of ventricular septal defects. Circulation. 1993;88 II205-9.

11. Murzi B, Bonanomi GL, Giusti S, Luisi VS, Bernabei M, Carminati M, et al. Surgical closure of muscular ventricular septal defects using double umbrella devices (intraoperative VSD device closure). Eur J Cardiothorac Surg. 1997;12:450-5.

12. Bacha E, Cao Q-L, Galantowicz M, Cheatham J, Fleishman C, Weinstein S, et al Multicenter experience with perventricular device closure of muscular ventricular septal defects. Pediatric Cardiol. 2005;26:169-75.

13. Thakkar B, Patel N, Shah S, Poptani V, Madan T, Shah C, et al. Perventricular device closure of isolated muscular ventricular septal defect in infants: A single center experience. Ind Heart J. 2012;64:559-67.

14. Bendaly EA, Hoyer MH, Breinholt JP. Mid-term follow up of perventricular device closure of muscular ventricular septal defects. Cathet Cardiovasc Interv. 2011;78:577-82.

15. Lim DS, Forbes TJ, Rothman A, Lock JE, Landzberg MJ. Transcatheter closure of high-risk muscular ventricular septal defects with the CardioSEAL occluder: initial report from the CardioSEAL VSD Registry. Cathet Cardiovasc Interv. 2007;70:740-4.

16. Michel-Behnke I, Ewert P, Koch A, Bertram H, Emmel M, Fischer G, et al Device closure of ventricular septal defects by hybrid procedures: a multicenter retrospective study. Cathet Cardiovasc Interv. 2011;77:242-51.

17. Zahn EM, Wilson N, Cutright W, Latson LA. Development and testing of the Helex septal occluder, a new expanded polytetrafluoroethylene atrial septal defect occlusion system. Circulation. 2001;104:711-6. 